\title{
DEMOCRACIA, RENOVACIÓN PEDAGÓGICA Y TERRITORIO RURAL: LA ESCUELA AGRÍCOLA COMARCAL VALENCIANA «LA SERRANÍA»
}

\author{
Democracy, Pedagogical Renewal and Rural Territory: The Valencian \\ Comarca Agricultural School «La Serranía»
}

\section{M. ${ }^{a}$ del Carmen Agulló Díaz ${ }^{\varphi}$ y Andrés Payà Rico ${ }^{\S}$}

Fecha de recepción: 02/04/2017 • Fecha de aceptación: 05/05/2017

Aprendimos a ver la importancia de lo que no se paga con dinero: levantarse para ver las escarchas del río [...]. Aprendimos a vivir con los placeres que no se compran, era importante la curiosidad, investigar [...]. ${ }^{1}$

Resumen. El surgimiento en Francia de las Maisons familiales d'apprentissage rural en los años 30 del siglo xx supuso la incorporación de la pedagogía activa y la cogestión a la formación profesional agrícola. Esta propuesta guiará las experiencias cooperativistas de las Escuelas Agrícolas Comarcales valencianas que se crearán en España en los últimos años de la dictadura franquista y se desarrollarán durante la transición política hacia la democracia, para dar respuesta a la demanda de una mejor formación y capitalización cultural del campo. Entre ellas cabe ubicar la existente en la población rural de Chulilla (Valencia), de la que nos ocupamos en el presente artículo y que ensayó acciones educativas de gestión democrática y renovación pedagógica. El análisis y estudio de esta breve pero significativa experiencia de la historia de la educación valenciana, nos muestra cómo una comunidad educativa puede construir una escuela crítica practicando la libertad y, de manera simultánea, mantener sus raíces. Recurriendo a las fuentes orales, hemos podido recuperar de la memoria de sus protagonistas, una parte de la historia de esta iniciativa cooperativa de educación rural, analizando tanto los presupuestos pedagógicos en los que se funda-

\footnotetext{
${ }^{\varphi}$ Departamento de Educación Comparada e Historia de la Educación. Facultad de Filosofía y Ciencias de la Educación. Universitat de València. Avenida Blasco Ibañez, 30, 46010 Valencia, España. m.carmen.agullo@uv.es

$\S$ Departamento de Educación Comparada e Historia de la Educación. Facultad de Filosofía y Ciencias de la Educación. Universitat de València. Avenida Blasco Ibañez, 30, 46010 Valencia, España. andres.paya@uv.es

${ }^{1}$ Entrevista de los autores al monitor de la escuela de Chulilla, Ximo Sánchez. 7/06/2008.
}

Cómo citar este artículo: Agulló Díaz, M. ${ }^{a}$ del Carmen y Andrés Payà Rico. «Democracia, renovación pedagógica y territorio rural: la escuela agrícola comarcal valenciana "La Serranía" ». Historia y Memoria de la Educación 7 (2018): 299-334. 
mentaba (metodología activa, alternancia, cogestión, democracia, formación integral, etc.), como su desarrollo en la práctica cotidiana.

Palabras clave: Cooperativas de enseñanza; Educación rural; Formación profesional; Historia de la educación valenciana; Renovación pedagógica.

Abstract. The emergence in France of the Maisons familiales d'apprentissage rural in the 1930s bought the inclusion of active pedagogy and codetermination to agricultural professional education. This approach impelled the experiments in cooperativism of the Valencian Escuelas Agricolas Comarcales that were created in Spain during the last years of Franco's dictatorship, and that were further developed during the political transition to democracy, in order to meet the demand for improved education and cultural capitalization of the countryside. Among these experiences, it is worth noting that of the rural population of Chulilla (Valencia - the subject of the following studyas it shows the implementation of educational practices based on democratic management and pedagogical renewal. The analysis and study of this brief but meaningful experience in the history of Valencian education reveals the way in which an educational community is able to build a critical school where freedom is practiced while at the same time holding on to its origins. By resorting to oral sources, we have been able to recover the memory of their protagonists, a part of the history of this cooperative initiative of rural education, analyzing both pedagogical assumptions on which it was based (active methodology, alternation, codetermination, democracy, personal development, etc.), as well as its development in daily practice.

Keywords: Educational cooperatives; Rural education; Vocational training; History of Valencian education; Pedagogical renewal.

\section{LA HISTÓRICA MARGINACIÓN DE LA ESCUELA RURAL Y LA FORMACIÓN AGRÍCOLA EN ESPAÑA}

Uno de los ámbitos más abandonados por las autoridades educativas de España ha sido, sin lugar a dudas, el rural. Tanto la escuela ubicada en estos espacios, como la formación agrícola de sus habitantes, han estado de manera sistemática ignoradas, cuando no menospreciadas, desde los mismos inicios de la construcción del sistema educativo.

Si nos remontamos a la ley Moyano (1857) encontramos las primeras referencias a esta problemática. En su articulado, en el currículum de las escuelas de enseñanza primaria de niños se contemplan unas Breves nociones de Agricultura, Industria y Comercio, que serían impartidas se- 
gún el carácter agrícola, industrial o comercial de las localidades en las que estuviera ubicado el centro docente. Al mismo tiempo, la ley incluía la asignatura de Nociones de Agricultura en el plan de estudios de formación del magisterio masculino. ${ }^{2}$

La obligatoriedad de cursar estas materias parece indicar una preocupación por parte del Estado por mejorar la formación de los agricultores, labradores y ganaderos que constituían en esos momentos el grueso del sector productivo. Sin embargo el hecho de impartirse mediante una enseñanza repetitiva, teórica, alejada de las necesidades y las prácticas reales, acompañada de escasez de materiales y manuales idóneos, y con un Magisterio escasamente preparado y motivado, condujo a un progresivo y acentuado divorcio entre escuela y sociedad rural.

Incluso la «revolución en la escuela» que propuso Rodolfo Llopis en la Segunda República, no afectaría de manera importante a las enseñanzas agrícolas ni a las zonas rurales. A pesar de las declaraciones de políticos y educadores sobre la necesidad de socializar el medio rural en los valores republicanos, y de edificar una escuela enraizada en el medio, las dificultades económicas y la corta duración de esta etapa histórica, hicieron que las esperanzas en ella depositadas se tornaran una vez más en frustración.

Aún así, y a pesar del fracaso global de la experiencia, de los años de la Segunda República, desearíamos mencionar algunos planteamientos que, en los últimos años del franquismo, serían recuperados por colectivos innovadores y se convertirían en guía de la renovación pedagógica de la formación agrícola.

Por una parte, destaca la reivindicación de la creación de escuelas en todas las poblaciones, entendiendo éstas como dinamizadoras de la sociedad rural. Así, el Consell de l'Escola Nova Unificada (CENU) catalán recomendaba:

Crear en cada pueblo su escuela o escuelas de ambiente rural. Crear escuela o escuelas politécnicas en el centro de cada comarca. Crear la escuela práctica de agricultura en las localidades

\footnotetext{
${ }^{2}$ Arts. ${ }^{\circ} 2$ y 68 de la SECCIÓN PRIMERA: De los estudios, TÍTULO I: De la primera enseñanza, y Titulo III: De las facultades y de las enseñanzas superior y profesional (Ley de instrucción pública de 9 de septiembre de 1857).
} 
bien situadas. Estudiar la conveniencia de concentración de escuelas en las comarcas de población diseminada. ${ }^{3}$

Y añadía, haciendo referencia a cual debía ser su orientación: «es vol que deixi de ser una còpia servil i empobrida de l'escola urbana per tenir la pròpia vida a partir de l'arrelament al medi que l'envolta, assajant nous plans de treball a partir dels recursos que ofereixen la natura i la vida». ${ }^{4}$

Así pues, en los años 30 del pasado siglo, podemos observar cómo ya se apuesta por una escuela enraizada en el medio, que utilice una metodología activa, crítica, opuesta a la tradicional pedagogía libresca, teórica y alejada de las prácticas agrícolas. En ella tendrían cabida los postulados de Pestalozzi, Decroly, Cousinet o Freinet; se abrían las puertas a nuevas experiencias como las Granjas-escuelas en donde el aprendizaje se realizaba sobre casos reales, o se intentaba que los manuales fueran sustituidos por ese gran libro que es la Naturaleza. ${ }^{5}$

Su finalidad era la de capacitar buenos profesionales, agricultores que supieran mejorar los cultivos de la tierra, gracias al aprendizaje de técnicas modernas y adecuadas, haciéndola más productiva, lo que redundaría en la economía local y nacional. Pero, sobre todo, se trataba de formar personas, hombres y mujeres que, más allá de una especialización, fueran ciudadanos críticos y activos. Un objetivo estrechamente vinculado a la dignificación de la profesión de agricultor, porque, a través de una estrecha relación entre el cultivo de la tierra y el amor a la misma, se buscaba provocar el deseo de la permanencia en las poblaciones, evitando con ello la emigración a las ciudades y el consiguiente despoblamiento de las zonas rurales.

Destaca, así mismo, el papel otorgado al maestro: misionero de la cultura — según la terminología de Rodolfo Llopis y Marcelino Domingo-, agente cultural, o, incluso, como prefería calificarlo, Herminio Al-

\footnotetext{
${ }^{3}$ La Escuela Nueva Unificada. Recopilación de antecedentes, comentarios y juicios críticos, junto con la obra desarrollada bajo los auspicios del CENU desde el 19 de julio de 1936 (Barcelona: Ediciones Españolas de la Revolución, 1938), 96.

${ }^{4}$ Josep González-Agàpito, Salomó Marqués, Alejandro Mayordomo y Bernat Sureda, Tradició i renovació pedagògica. 1898-1939 (Barcelona: Institut d'Estudis Catalans. Publicacions de l'Abadia de Montserrat, 2002), 522.

${ }^{5}$ Juan Manuel Fernández Soria y M. ${ }^{a}$ del Carmen Agulló Díaz, «El problema de lıescola rural durant la Segona República», Educació i història: Revista d'història de l'educació, 8 (2005): 29-62.
} 
mendros, «maestro proletario». Denominaciones todas ellas que tienen en común la exigencia de una dedicación total a su tarea educativa, un compromiso con «la causa del pueblo, con una dedicación altruista que posibilite conseguir una auténtica educación popular». ${ }^{6}$

Desafortunadamente, el franquismo no centraría sus preocupaciones ni en la escuela ni en la formación del alumnado rural. Sólo algunos pedagogos destacados de la dictadura como Agustín Serrano de Haro o Adolfo Maíllo, redactarían estudios que recogían propuestas para mejorar la enseñanza en el campo, aunque, al no estar acompañadas de recursos materiales ni de voluntades políticas claras, ocasionarían su fracaso, manteniendo altos índices de analfabetismo, el progresivo abandono de las tierras y el éxodo a las zonas urbanas.

La formación profesional agrícola, como el resto de la formación profesional, se vería inmersa, en esta época, en una tupida red de leyes, centros e instituciones educativas que dificultaron su regulación y eficacia. ${ }^{7}$ Recordemos que se promulgó la Ley de Bases de Formación Profesional (16/07/1949) mediante la que se institucionalizó el Bachillerato Laboral que sería impartido en los Institutos Laborales, en la que se incluían las modalidades agrícola-ganadera, marítimo pesquera e industrial-minera. El predominio de la agrícola-ganadera reflejaba la intención de mejorar la formación de los agricultores, debido a las exigencias económicas de esta etapa del franquismo. La existencia de dos bachilleratos, y de dos centros docentes separados para impartirlos, es una muestra del clasismo inherente a los presupuestos del nacional-catolicismo.

La posterior Ley de Formación Profesional Industrial (20/07/1955) establecería cuatro grados de enseñanza: Pre-aprendizaje; Orientación y aprendizaje; Maestría y Perfeccionamiento, impartidas en Escuelas de Preaprendizaje, Aprendizaje y Maestría, que dependían del Ministerio de Educación Nacional (MEN).

Pero se mantiene la diferencia entre centros oficiales, dependientes del Ministerio de Educación Nacional y reconocidos, pertenecientes a la

\footnotetext{
${ }^{6}$ Herminio Almendros, «La escuela rural», Revista de Pedagogía, 145 (1934): 11.

${ }^{7}$ Andrés Payà Rico, «Formació professional, instrucció i adoctrinament a l'empresa Segarra (la Vall d'Uixò, Castelló) durant el franquisme», Educació i Història. Revista d'història de l'educació, 15 (2010): 229-252.
} 
Iglesia, a la Organización Sindical, a organismos privados, a empresas..., un auténtico caos que diversifica los currículums, las metodologías y las titulaciones. ${ }^{8}$ Además, en todas las modalidades se aplicaba el principio de separación de sexos y feminización del currículum, adaptando, tanto el Bachillerato Laboral como las enseñanzas técnicas y contenidos a las consideradas características femeninas. ${ }^{9}$

Finalmente, en el contexto de la promulgación de la Ley General de Educación, de 1970, el aumento de la obligatoriedad de la escolarización hasta los 14 años y la educación permanente abrían diferentes posibilidades para la educación. En este sentido, el artículo veintiséis contemplaba para el bachillerato que «las enseñanzas y actividades técnico-profesionales serán también fijadas por el Ministerio de Educación y Ciencia y se referirán a los sectores de actividades agropecuaria, industrial, comercial, náutica-pesquera, administrativa, artística y otras que se consideren adecuadas». ${ }^{10}$ Sin embargo, al mismo tiempo, la desafortunada política de las concentraciones escolares, continuaba provocando la despoblación del territorio rural.

La Ley también reformaba la Formación Profesional, diviéndola en dos etapas: FP1 y FP2, que podían ser cursadas de manera independiente. La agrícola estaba incluida en los dos niveles, y sería impartida en centros específicos de formación profesional agrícola, en ocasiones ubicados en zonas rurales. Es a partir de este momento cuando surgen iniciativas renovadoras como las Escuelas Familiares Agrarias y los Colegios Familiares Rurales, de los que nos ocuparemos a continuación.

\footnotetext{
${ }^{8}$ Los centros oficiales eran los fundados y regidos por el MEN. Los no oficiales dependían de la Iglesia, del Movimiento, del Ejército, del Sindicato Vertical, de Diputaciones o Cabildos, Ayuntamientos y Mancomunidades, así como de Montepíos o Mutualidades de Previsión, Federaciones, empresas y entidades o personas privadas. Como muestra de este caos de centros educativos e Instituciones, recordemos que en 1950, respecto a la formación agrícola existían Institutos laborales (Bachillerato Laboral); Escuelas de Formación profesional, entre las que se incluían las de Capacitación Agraria; Formación Intensiva; Centros Sindicales de Formación Profesional..., pudiendo depender estos centros tanto del Ministerio de Trabajo, como del de Educación o Agricultura.

${ }^{9}$ Para ampliar la feminización de la enseñanza agrícola puede consultarse M. ${ }^{a}$ del Carmen Agulló Díaz, «De ignorada a necesaria: la formación professional de las mujeres en el franquismo (19361975)». En Entre lo doméstico y lo público. Capacitación profesional de las mujeres rurales en España (1940-1977), ed. Sara Ramos Zamora (Madrid: Biblioteca Nueva, 2016), 45-72.

${ }^{10}$ Ley 14/1970, de 4 de agosto, General de Educación y Financiamiento de la Reforma Educativa. Boletín Oficial del Estado, núm. 187, de 6 de agosto de 1970, 12525-12546.
} 
INFLUENCIAS RENOVADORAS EN LA FORMACIÓN AGRÍCOLA: LAS PROPUESTAS PEDAGÓGICAS DE LAS ESCUELAS FAMILIARES AGRARIAS Y LOS COLEGIOS FAMILIARES RURALES

Entre las diferentes propuestas de renovación pedagógica aplicadas a la formación agrícola cabe destacar, por su influencia en España, la de las Maisons Familiales d'Apprentissage Rural francesas, que surgieron en 1935 bajo la influencia del abad Granereau, en Lauzun, (Lot-et-Garonne, Francia).

Tres son los principios que caracterizarían este modelo, y que, en síntesis, serían:

- La alternancia: alternar períodos de residencia y convivencia del alumno entre la escuela y su domicilio (una semana o quince días en cada espacio).

- La cogestión: responsabilidad compartida de padres, alumnos y docentes, en la creación y sostenimiento del proyecto, tanto desde el ámbito económico como en el de la gestión administrativa.

- La adopción de una metodología activa concretada en el denominado Cuaderno de explotación familiar o del medio, que sustituiría a los libros de texto convencionales, estableciendo dobles vínculos entre escuela y familia, y una enseñanza agrícola y contenidos de carácter más general.

Las Maisons configuran, en síntesis, «una propuesta de escuela activa, que intenta una formación integral a través de la cooperación y la participación, permitiendo arraigar al alumno en su medio social». ${ }^{11}$

Su éxito hizo que en plena España franquista, de la mano de la Iglesia católica, se crearan los primeros centros docentes basados en su modelo pedagógico. Así, de los estudios que realizó el Centro de Iniciativas para la Formación Agraria (CIFA) de Sevilla, con una ayuda de la Confederación

\footnotetext{
${ }^{11}$ Para un mayor conocimiento de la propuesta puede consultarse: M. ${ }^{a}$ del Carmen Agulló Díaz y Andrés Payà Rico, «La influencia de las Maisons familiales d'apprentissage rural en las escuelas comarcales de formación agrícola valencianas (1973-2008)». En Influencias francesas en la educación iberoamericana (1808-2008), coord. José María Hernández Díaz, (Salamanca: Globalia Ediciones Anthema, 2008), 275-288, y M. ${ }^{a}$ del Carmen Agulló Díaza y Andrés Payà Rico, Les cooperatives d'ensenyament al País Valencià $i$ la renovació pedagògica i social (1968-1976) (Valencia: Universitat de València, 2012).
} 
española de Cajas de Ahorros, surgieron en 1965 dos opciones diferentes, seguidoras con matices de la metodología francesa.

Una propuesta serían las Escuelas Familiares Agrarias (EFA), promovidas por Joaquín Herreros Robles, Felipe González de Canales y Francisco Molina Sánchez. Vinculadas al Opus Dei, fueron impulsadas por José María Escrivá de Balaguer «quien advertía la necesidad de promover la mejora de las condiciones de vida y de trabajo de los habitantes del medio rural». ${ }^{12}$ Contaron con el apoyo económico de las cajas de ahorros y abrieron sus primeros centros docentes, Casablanquilla (Brenes) y Molino Azul (Lora del Río), ambos en la provincia de Sevilla, en octubre de 1967. Estas dos iniciativas se extendieron por el territorio español formando una amplia red de escuelas.

Otra opción fueron los Colegios Familiares Rurales (CFR) promovidos por D. Félix Silicio, consiliario de Acción Católica, y María Luisa Jolín, quienes abrirían los dos primeros colegios, también en octubre de 1967, en Medina de Rioseco y Tudela de Duero, en la provincia de Valladolid. En este caso, los vínculos con la Iglesia católica se establecen a través de los denominados movimientos apostólicos cristianos: JARC (Juventud Agrícola Rural Católica), HOAC (Hermandades Obreras de Acción Católica) y JOC (Juventud Obrera Católica). Su área de extensión fue Castilla y León y Galicia, ${ }^{13}$ quedando agrupados en la Federación de Colegios Familiares Rurales (FCFR).

Ambas propuestas, siguiendo los tres principios de las Maisons, coinciden en basar su pedagogía en la adopción de la alternancia, la cogestión y los Cuadernos de Explotación y del medio, mientras que se distinguen en tres aspectos: las EFA siguen el precepto de la segregación de sexos, ${ }^{14}$ implantan una uniformidad organizativa, y mantienen una ideología vin-

\footnotetext{
${ }^{12}$ Unión de Escuelas Familiares Agrarias (UNEFA) http://www.unefa.org (consultado el 31-1-2017).

${ }^{13}$ A los colegios de Tudela de Duero y Medina de Rioseco se añadieron los de Mayorga de Campos y «El Pino» (Valladolid), Toro (Zamora), Santa María del Páramo, Posada del Bierzo, Gradefes, Carrizo de la Ribera, y Bárcena del Caudillo (León), Oropesa (Toledo), Frómista y Astudillo (Palencia), Aranda de Duero (Burgos), Barco de Ávila, Candeleda y Fresnillo (Avila); Ramales de la Vitoria, Liérganes, Arenas de Iguña y San Vicente de Toranzo en Cantabria; y Negreira y Vimianzo (A Coruña), Ribadavia, Celanova, Xinzo de Limia y Verin (Ourense). En «Situación del mundo rural. Los Colegios familiares rurales», Militante: Apostolado Rural, 95 (1974): 10.

${ }^{14}$ Recomendado en la Encíclica Divinus Illius Magister (31 diciembre 1929) para los centros católicos, lo que conllevaba fundar centros masculinos y femeninos.
} 
culada al sector más conservador del catolicismo. Por su parte, los CFR establecieron la coeducación, la heterogeneidad en la organización, y el seguimiento de los presupuestos de la pedagogía de la liberación, en especial los de Paulo Freire. El objetivo final es, en ambos casos, formar integralmente al alumnado, trascendiendo la mera especialización profesional para educar personas.

Con sus coincidencias y diferencias, cincuenta años después se mantienen los dos modelos, agrupándose las EFA en la UNEFA (Unión de Escuelas Familiares Agrarias) ${ }^{15}$ y los CFR en COCEDER (Confederación de Centros de Desarrollo Rural). ${ }^{16}$

\section{EL MODELO DE LAS MAISONS EN VALENCIA}

En la provincia de Valencia, a finales del pasado siglo, existían escasos centros de formación profesional agraria. De carácter básico podemos mencionar dos escuelas primarias nacionales de orientación agrícola: la Granja Moroder (Montcada) y la del Pla del Pou (Paterna); así como el Instituto Laboral de Alzira (1951) donde se impartía la rama agrícola-ganadera. También existían, para la formación de jóvenes, dos Escuelas de Capataces (Catarroja, 1956, y Requena, 1961).

A rasgos generales, el panorama tendría que calificarse como desolador, ya que en una economía como la valenciana, que continuaba siendo eminentemente agraria, esta falta de capacitación repercutía en una escasa rentabilidad de la tierra cultivada y, en consecuencia, en el despoblamiento progresivo de las zonas rurales.

En los últimos años del franquismo, un grupo de personas vinculadas al movimiento cooperativo a través de la cooperativa de servicios Equip Gerencial, denominada años más tarde Coinser (Cooperativa Industrial de Serveis), ${ }^{17}$ fundarán las primeras escuelas de formación agrícola va-

\footnotetext{
${ }^{15}$ Ver http://www.unefa.org/index.phper (consultado el 20-1-2017).

${ }^{16}$ Ver http://www.coceder.org/ (consultado el 20-1-2017).

${ }^{17}$ El Equip Gerencial sería fundado por Vicent Diego, Paco Pons Aloi, Josep Maria Soriano Bessó, Toni Ferrer y Luis Valero, y se legalizará en 1975, denominándose Coinser. Vinculados a la JARC, deseaban crear un grupo cooperativo que siguiera las líneas de la experiencia de Mondragón, es decir, que promocionara los sectores cooperativos del trabajo asociado, del consumo y de la enseñanza. Con este objetivo, en el transcurso de los años, crearon cooperativas de viviendas, de consumo (su-
} 
lencianas, que seguirán el modelo de las Maisons en un intento de dar respuesta a la falta de centros capaces de formar agricultores mediante una metodología activa y con contenidos relacionados con sus intereses.

El grupo cooperativo decide seguir el modelo de las EFA y abre su primer centro, la Escola Comarcal l'Horta, en Villa Carmen ${ }^{18}$ (Catarroja, L'Horta, 1973). Organizada bajo la forma jurídica de cooperativa de padres de alumnos, con alumnado exclusivamente masculino, contará con un equipo docente formado por Joan Ramon Peris, Ferran Martínez y Albert Taberner, quienes habían acudido a Almodóvar del Rio para realizar, durante una semana, el curso de monitor que impartía González de Canales, poniéndose en contacto con la metodología y los principios que inspiraban las EFA.

A ellos se añadirían colaboradores externos como Josep M. ${ }^{a}$ Soriano Bessó, Lluís Font de Mora y Josep Lluis Pitarch. ${ }^{19}$

Tras la experiencia del primer curso, se decide cambiar de modelo y establecer el de los CFR. Su desvinculación de las EFA, y su inclusión en la estructura estatal de los CFR, fue causada por considerar esta línea pedagógica más acorde con el cooperativismo valenciano, con fuertes raíces en la JARC. El cambio implicaba la asistencia a los cursos de Valladolid para la formación de los monitores, el intercambio de experiencias y materiales, y la posibilidad de combinar la mirada cercana, el arraigo al medio local y comarcal, con la más amplia de todo el Estado, frente a la tentación de posibles defectos de localismo, al mismo tiempo que se respetaban las particularidades de cada territorio.

En el curso 1974-1975 continúa la experiencia de Catarroja y da comienzo a sus actividades la Escola de Formació Agrícola Comarcal de La Safor (Beniarjó, La Safor, 1974), con treinta alumnos de ambos sexos y los monitores Albert Taberner y Ferran Martínez, iniciadores de la expe-

permercados Consum), de crédito (Caixa Popular), industriales, y cooperativas de enseñanza, entre las que cabe citar La Nostra Escola Comarcal (infantil y primaria) y las Escuelas Comarcales Agrícolas. 18 «Villa Carmen» será el edificio que albergará, durante los primeros meses del curso 1973-74, la Escola Comarcal l'Horta y La Nostra Escola Comarcal. Para profundizar en el tema, véase M. ${ }^{a}$ del Carmen Agulló Díaz y Andrés Payà Rico, «La Nostra Escola Comarcal: An Educational Cooperative in Defense of Democratic, Active and Valencian Pedagogy (Spain: 1973)» en Pedagogies and Curriculums to (Re) imagine Public Education, (New York: Springer, 2015), 187-202.

${ }^{19}$ En cursos siguientes el equipo docente estaría formado por Benet Delcán, Miquel Albert, Joan Ramon Peris, Carmen Albors, colaborando Josep Tarrassó, Isabel Romero y Josep M. ${ }^{a}$ Soriano. 
riencia de l'Horta que se trasladarían a Beniarjó para fundar el centro. Ya en el curso 1976-1977, a las dos experiencias en funcionamiento se añadirá una tercera, la Escola de formació agrícola comarcal La Serranía, ubicada en Chulillla (La Serranía).

Los objetivos que en ellas se pretendían alcanzar pueden resumirse en tres: a) preparar a los futuros agricultores de una manera integral, en los ámbitos profesional, técnico, intelectual, y, sobre todo, en el humano; b) recuperar las vocaciones agrícolas, para evitar el despoblamiento, modernizando el campo; y c) implicar a los agricultores en el medio social y cultural, dignificando la lengua propia, y haciéndolos conscientes de la necesidad de construir comarca y país. Para ello, adoptaron los tres presupuestos pedagógicos de las Maisons y los adaptaron a la realidad del medio rural valenciano, estableciendo la alternancia, la cogestión y la metodología activa.

De las tres experiencias, nos detendremos a analizar con detalle la llevada a cabo por la Cooperativa Agrícola Comarcal, La Serranía, debido a que, a pesar de ser la de menor duración temporal, ejemplifica perfectamente la plasmación en la práctica de los principios pedagógicos de las Maisons, con sus dificultades y sus aciertos.

\section{LA SOCIEDAD COOPERATIVA DE ENSEÑANZA ESCOLA DE FORMACIÓ AGRÍCOLA COMARCAL LA SERRANÍA (CHULILLA) ${ }^{20}$}

La comarca de La Serranía, al noroeste de la provincia de Valencia, limítrofe con Cuenca y Teruel, era una zona en donde el retraso económico y social, con resquicios de un caciquismo decimonónico en el ámbito político, frenaba toda posibilidad de expansión, siendo la emigración y el despoblamiento la perspectiva que, a corto plazo, contemplaban sus habitantes a finales de los años 70 del pasado siglo.

En este marco socio-económico y político, concretamente en la población de Chulilla, se creó la tercera de las escuelas agrícolas de forma-

\footnotetext{
${ }^{20}$ La corta duración de la experiencia de Chulilla, unida a su súbito final y la falta de bibliografía sobre ella, ha hecho que no se pueda disponer de documentación escrita. Agradecemos de manera especial a Vicent Borrás, Rafael Gil, Ximo Sánchez, Benet Delcán y Josep Maria Soriano sus testimonios que nos han permitido reconstruir su historia, basada, por tanto, en fuentes orales, con la riqueza y los riesgos que estas comportan.
} 
ción profesional agraria que se promovieron desde el Grup Cooperatiu Valencià.

En 1976, en plena transición política y de expansión del grupo cooperativo, Josep María Soriano Bessó, principal coordinador de las iniciativas mencionadas, contactó con dos agentes del Servicio de Extensión Agraria y el sacerdote Vicente Juan, de la localidad de Chelva, quien coordinaba a los otros sacerdotes de la comarca con el objetivo de crear un nuevo centro.

Sería el grupo de sacerdotes, junto con Josep María Soriano y Manolo García, quienes llevaran a cabo la gestión de constitución de la escuela, consiguiendo y organizando los recursos económicos y humanos necesarios. A ellos deben añadirse Joan Ramón Peris y Benet Delcán, monitores de la Escuela de Catarroja y con experiencia en este ámbito, en quienes el Grup delegó las tareas de puesta en marcha de la escuela.

La fuerte implicación de los sacerdotes de la comarca en el proyecto muestra con claridad los estrechos vínculos entre las personas miembros del cooperativismo y la JARC, porque, si bien en las otras dos escuelas este movimiento apostólico católico había tenido gran protagonismo, en buena medida por la militancia de los monitores, ahora se puede comprobar tanto a la hora de determinar su ubicación, como en el modelo de captación de socios y alumnos.

Por esta razón, a la hora de decidir en qué población se establecía la escuela, el criterio fue utilizar un albergue que había inaugurado en Chulilla hacía tres años la JARC, con el fin de realizar en verano actividades de carácter lúdico y formativo. Las instalaciones eran muy adecuadas para la finalidad educativa que se perseguía: un edificio ancho, de nueva planta, dotado de habitaciones, cocina, etc., del que se podía disponer de manera inmediata porque su utilización por el movimiento católico era durante el verano, coincidiendo con el período vacacional del alumnado.

Como contrapartida, su emplazamiento en el extremo y no en el centro de la comarca, fue un factor que, a la hora de valorar la viabilidad de la experiencia, se dejó en un segundo plano, y, sin embargo, a corto plazo dificultó su asentamiento debido a la dificultad de las comunicaciones entre las poblaciones por las características orográficas y la falta de infraestructuras que facilitasen los desplazamientos. 
La otra influencia de la JARC, radica en que todos los sacerdotes de las poblaciones implicadas en la creación de la escuela habían estado o estaban vinculados a esta organización juvenil católica, en especial Vicente Juan (Chelva), Vicent Angla Sanfeliu (Calles) y Vicente Berenguer (Titaguas), además del de Aras de Alpuente, Juan ${ }^{21}$ y Miguel Polo, de Chulilla. Los sacerdotes contribuyeron de manera determinante a la configuración y sostenimiento de la escuela, que siempre contó con escasos recursos económicos, hasta el punto de que, en ocasiones, como recuerda Vicent Borrás, eran ellos quienes proporcionaban cena y alojamiento a los monitores en los viajes de desplazamiento por la comarca, cuando, debido a las deficientes condiciones de las carreteras, no podían volver a pernoctar a Chulilla.

Esta implicación tan directa del clero en la constitución de la escuela responde al ideal formativo de la JARC de dotar a los habitantes de las zonas rurales de una formación que les ayudara a promocionarse por sí mismos y a sus poblaciones; es decir, una educación «que exige una promoción de nuestros pueblos, de tal manera llevada a cabo que haga de sus moradores los propios protagonistas de su elevación y puesta en línea de progreso». ${ }^{22}$

La escuela de Chulilla nació, por tanto, con idéntica intencionalidad que todos los Colegios Familiares Rurales: dar respuesta práctica a una de las necesidades más apremiantes del mundo rural, la educación de los adolescentes sin separarlos de su medio.

La fórmula que adoptaron sus promotores fue la de una cooperativa de consumo, formada por los padres y madres de alumnos de las poblaciones de Chulilla, Calles, Chelva, Tuéjar, Titaguas, Aras, Alpuente, Valdovar, la Cueva Ruz, Campoabajo, La Yesa, Abejuela y Santa Cruz de Moya $^{23}$ empezando las clases del primer curso en el albergue de la JARC de Chulilla en octubre de 1976. El segundo transcurrió entre los años 1977 y 1978, siendo el tercero el curso 1978-1979, cuando hubo de tras-

\footnotetext{
${ }^{21}$ No ha sido posible conocer el apellido.

22 «El Movimiento Rural en las Diócesis. Valencia», Militante Apostolado Rural, 26 (1968): 10.

${ }^{23}$ Aunque la población de Abejuela pertenece a Teruel y Santa Cruz de Moya a Cuenca, también asistía alumnado de estos pueblos, al no existir posibilidad de capacitación agrícola en su zona y estar geográficamente dentro del área de influencia de La Serranía.
} 
ladarse en el último semestre a la localidad de Villar del Arzobispo por dificultades de todo tipo, fundamentalmente de índole económica.

\section{Una cooperativa de padres y madres agricultores}

La titularidad de la escuela correspondía a los padres y madres, todos ellos trabajadores del campo, y se regía en su organización y gestión por los organismos de carácter asambleario y democrático propios del régimen cooperativo: Asamblea General de socios, Junta Rectora y Junta de Vigilancia.

Ahora bien, en el día a día serían, en buena medida, los maestros-monitores quienes la gestionaron, al haber depositado los padres su confianza en ellos gracias al establecimiento de una excelente relación. Por ello, las reuniones se pudieron reducir a un máximo de tres o cuatro durante todo el año, evitando las molestias derivadas de los desplazamientos a través de unas deficientes infraestructuras.

Este clima se conseguía manteniendo el contacto familiar mediante las visitas de los monitores a los domicilios del alumnado durante la semana de alternancia. En ellas se intercambiaban opiniones en relación con los hijos y su evolución, convirtiéndose en auténticas tutorías. También los padres podían desplazarse a la escuela, siendo acompañados, en ocasiones, por alguno de los sacerdotes para dialogar con los monitores.

Ximo Sánchez apunta que la alternancia y la tutoría, eran «momentos y espacios de encuentro entre padres, alumnos y monitores, favoreciendo su implicación, de forma que los monitores eran cómplices de padres y alumnos, facilitando una evolución conjunta de todos». ${ }^{24}$

Los recursos económicos fueron, desde sus inicios, muy escasos por las graves dificultades económicas de las familias y la carencia de apoyo institucional.

Para poder empezar, el grupo Coinser pudo gestionar un crédito de 300.000 pesetas de Caja Rural, al que se añadieron las becas del Ministerio de Educación que se socializaron, poniendo todo el dinero en común, de forma que todo el alumnado, disfrutara o no de ella, no pagaba nada

\footnotetext{
${ }^{24}$ Entrevista de los autores al monitor de la escuela de Chulilla, Ximo Sánchez (7/06/2008).
} 
ni por la estancia ni por la manutención, siendo el autobús, que trasladaba los lunes alternos al alumnado a Chulilla tras pasar por todos los pueblos y los regresaba el sábado, el único gasto que corría a cargo de los padres. No se pudieron conseguir, sin embargo, otras subvenciones o aportaciones de organismos, asociaciones o instituciones de la zona, razón por la cual las dificultades económicas marcaron la escuela desde su fundación.

Cabe recordar que, aunque eran tiempos de transición a la democracia, la mayoría de los ayuntamientos de la comarca permanecían en manos de alcaldes franquistas, que no veían de manera satisfactoria una escuela que nacía relacionada con personas que, aunque vinculadas a la Iglesia, eran consideradas críticas e, incluso, denominadas como subversivas. La carencia de apoyo insitucional por parte de la administración local, agravada en ocasiones por el claro boicot de ayuntamientos y otros organismos oficiales, sería condicionaría la corta duración de esta experiencia educativa.

\section{Un alumnado diverso y de procedencia rural}

La escuela comenzó su camino con una matricula inicial de 35 alumnos, aunque hubo algunos abandonos, siendo finalmente 23 (quince alumnos y ocho alumnas). La procedencia territorial del conjunto del alumnado era variada, ya que pertenecían a diferentes pueblos de la comarca o sus alrededores: Chulilla, Calles, Chelva, Titaguas, Aras de Alpuente, Alpuente, Valdovar, Cueva Ruz, Campoabajo, La Yesa, Abejuela y Santa Cruz de Moya.

Destaca el elevado porcentaje de mujeres matriculadas, teniendo en cuenta que la rama agrícola no era socialmente considerada femenina, lo que provocaba que fueran escasas las que se decídían a cursarla. Pero el peso de las mujeres en la zona de Alpuente, en donde era la madre quien tomaba la decisión los estudios de los hijos y las hijas, hizo que aumentara su presencia en la escuela, siendo la zona de Alpuente precisamente la de mayor procedencia de alumnas (tres de Titaguas, una de Alpuente y una de Aras). En el segundo año se añadieron dos de Higueruelas y cuatro de Domeño. 
Desde la perspectiva del alumnado esta diversidad fue positiva, porque permitió encontrarse y establecer relaciones entre chicos y chicas de pueblos alejados entre sí. Sin embargo, dificultaría la práctica de la tutoría en la semana de residencia con la familia.

Respecto a la edad, variaba entre los catorce y los dieciséis años, ya que se incorporaban cuando finalizaban la educación primaria.

En lo que concierne a la procedencia familiar, eran hijos de familias de agricultores, que vivían de la tierra, por lo que conocían bien las tareas agrícolas, aunque un porcentaje importante había fracasado en el mundo escolar, no habiendo sido voluntaria la elección de cursar formación profesional, sino que se vieron abocados a ella por su fracaso en los estudios precedentes.

Debido a esta calificación de fracasados y marginados, la importancia del diálogo y los sentimientos, del trato humano y personal, del respeto e incluso del cariño de los monitores y compañeros para que se sintieran valorados, era muy relevante, posibilitando que pudieran extraer el máximo de sí mismos y realizaran un correcto aprendizaje. Vicent Borrás apunta que no tuvieron nunca ningún problema:

de gent que se descolgara ni res. Crec que tots tiraren endavant, alguns inclús han fet carrera universitaria. Me'n recorde d'un de Chulilla que va fer enginyer tècnic agrícola. L'escola tenia un gran nivell de coneixements perquè el material didàctic que teniem des de Valladolid era molt modern i molt bo per a l'època. ${ }^{25}$

En el curso 1977-1978 finalizó esta primera promoción y comenzó la segunda que sería también la última al tener que cerrarse la escuela en 1979.

\section{Un equipo de monitores-educadores implicado pedagógica y socialmente}

El papel del monitor-educador era determinante en las escuelas. Se les exigía, más allá de la capacitación docente y técnica, el compartir una

\footnotetext{
${ }^{25}$ Entrevista de los autores al monitor de la escuela de Chulilla, Vicent Borrás Sena (10/06/2008).
} 
serie de valores de carácter humanístico, de justicia social, de igualdad, de compromiso social, y además saber trabajar en equipo.

Albert Taberner, uno de los monitores que trabajaron en las escuelas de formación agrícola de Catarroja y Beniarjó, comentaba que la mayoría de los monitores procedían de la JARC, un movimiento que

intentava estar present en el món rural, promocionant uns valors de justícia social, d'igualtat, de solidaritat, del compromís social. La paraula compromís recorde que era i continua sent una paraula clau en l'educació de les persones, la gent s'ha de comprometre en el seu entorn, una persona que es comprometa en el seu entorn, crec que és una persona plena de valors [...]. El primer impuls és un impuls generós de voler estar junt amb els teus, per a que avance un model social determinat que pot ser més conservador o més progresista. En aquell moment la JARC era molt progressista. I de fet de la JARC jo crec que eixiren dirigents sindicals, dirigents polítics, que es mogueren i acabaren situant-se al final en diferents partits. ${ }^{26}$

El compromiso social, sería, por lo tanto, la señal distintiva de los monitores, traducido, además de en su trabajo pedagógico, que seguía los parámetros de una pedagogía popular, en su incorporación a partidos políticos de izquierda y sindicatos. Este compromiso los acercaría al alumnado y a sus familias, aunque sería causa de dificultades con las autoridades políticas del momento.

Por otra parte, el trabajo en equipo, como apuntaba Jesús Muñoz Peinado:

constituía una de las columnas básicas para un buen funcionamiento de los CFR. Allí donde se lograba el funcionamiento del equipo, las cosas marchaban bastante bien. Donde no se conseguía equipo, los cambios de personal introducían una variable

\footnotetext{
${ }^{26}$ Entrevista de los autores al monitor de las escuelas de Catarroja y Beniarjó, Albert Taberner i Ferrer (14/02/2008).
} 
muy importante que afectaba a la estabilidad y a la buena organización del colegio. ${ }^{27}$

El equipo de maestros que empezó el primer curso en Chulilla estaba formado por tres personas sin experiencia previa en el mundo de las escuelas agrarias rurales, aunque sí en el de la docencia, siendo el monitor responsable, Vicent Borrás Sena, ingeniero técnico agrícola, de Carlet, que había estado vinculado anteriormente a la JARC, y que, al asistir a la primera Escola d'Estiu valenciana, conoció el proyecto cooperativo de formación agrícola y se interesó por él, decidiendo incorporarse al mismo. Para ello hubo de realizar el curso previo de formación en Tudela del Duero (Valladolid), donde tomó contacto con una pedagogía «molt participativa, activa $\mathrm{i}$ assembleària». ${ }^{28}$

Entusiasmado con el proyecto convocó a dos compañeros suyos, Carmina Peinado, maestra, y Quique Miró Blanes, licenciado en física, para que le acompañasen, formando el primer equipo de Chulilla, quienes intentaron solucionar su falta de experiencia en la formación profesional agrícola, coordinándose con las otras dos cooperativas valencianas de Beniarjó y Catarroja.

En el segundo curso se renovó el equipo de monitores: Vicent Borràs y Carmina Peinado lo abandonaron, Quique Miró continuó, y se incorporaron al equipo Rafael Gil Cortés, maestro, Ximo Sánchez, técnico agrícola, y Tere, que sólo estaría este curso. Rafael Gil, como era preceptivo, antes de incorporarse asistió a los cursos formativos de Tudela de Duero, aprendiendo intensivamente en una semana elementos de planificación, valoración dinámica, administración y pedagogía. En el último curso, el equipo de monitores se vería reducido a Ximo Sanchis, Rafa Gil y la maestra M. José Jiménez, siendo los tres naturales de la comarca de La Serranía y buenos conocedores de la misma. ${ }^{29}$

\footnotetext{
${ }^{27}$ Jesús Muñoz Peinado «Los colegios familiares rurales», Revista Interuniversitaria de Formación del profesorado, 17 (3), (2003): 84.

${ }^{28}$ Vicent Borrás había pertenecido a la JARC en Carlet, y allí se relacionó con Honori Pascual, que fue compañero de curso en el Seminario del grupo de sacerdotes de La Serrania. Entrevista de los autores al monitor de la escuela de Chulilla, Vicent Borrás Sena (10/06/2008).

${ }^{29}$ Entrevista de los autores al monitor de la escuela de Chulilla, Rafael Gil Cortés (27/02/2009).
} 
Cabe destacar, a pesar de los cambios, el mantenimiento de un buen trabajo en equipo de los monitores, siendo esta una de las causas de satisfacción del alumnado.

Por otra parte, hay que mencionar que la razón de incorporarse y permanecer en el proyecto se debía a presupuestos de carácter social, en ningún caso económico, ya que la retribución, fijada por la Federación de escuelas que establecía un sueldo orientativo, era insuficiente. La comida y el alojamiento estaban cubiertos, pero no se cobraba un salario de manera fija, y, además, la necesidad de trasladarse a los domicilios del alumnado para realizar las visitas ocasionaba un fuerte gasto de combustible, que se traducía en un desembolso económico considerable.

Esta situación fue causa de abandono del proyecto de algunos monitores que querían comenzar proyectos de vida con una cierta estabilidad. Pero la mayoría permanecieron, porque como decía Vicent Borrás, eran unos idealistas: «entonces ens menejavem més pel tema sentimental i polític, erem més romàntics». ${ }^{30}$

Al igual que en la Segunda República, la asunción en los ilusionantes años de la transición del papel de «maestro proletario» aparece como modelo de los monitores-educadores, altruistas, identificados con la causa del pueblo y defensores de una pedagogía humanista, crítica y revolucionaria, transformadora de conciencias y sociedades.

\section{Una formación integral, profesional y humana}

Durante los cursos que duró la experiencia, se impartieron dos ramas correspondientes al primer grado de formación profesional, la agrícola y la de secretariado (administrativo). Aunque la formación agrícola era la que interesaba difundir, para poder alcanzar una matrícula suficiente se implantó la que capacitaba para la administración, con mayor prestigio social y aceptación mejor por las mujeres.

Ahora bien, realmente lo que se pretendía era combinar la formación intelectual y profesional con la personal; es decir, construir una escuela más humana, con una enseñanza que tuviera como objetivo y centro la persona, para lo que se utilizarán principios pedagógicos de autores muy

\footnotetext{
${ }^{30}$ Entrevista de los autores al monitor de la escuela de Chulilla, Vicent Borrás Sena (10/06/2008).
} 
diversos, entre los que se encuentran Carl Rogers, -la confianza hacia el alumnado-, Paulo Freire, —con sus planteamientos personalistas-, Decroly —la globalización-, Makarenko — la introducción del trabajo productivo—, Neill —la educación en libertad—, Lorenzo Milani —la importancia de la palabra-, y, sobre todo, Freinet —la cooperación y la metodología «yo critico, yo opino, yo propongo»-.

Como apunta Juan Vicente Blasco, educar significa ayudar a reflexionar y proporcionar pistas para la resolución de conflictos; por ello «la Escuela está plenamente convencida [de] que, creando un clima afectivo dentro de la misma, es decir si se posibilita un ambiente donde se encuentre aceptado, se encontrará seguro de él mismo y capaz de desarrollar al máximo todas sus responsabilidades». ${ }^{31}$

En definitiva, se practica una pedagogía centrada en la persona y el medio natural, social y cultural como fuente de aprendizaje y, al mismo tiempo, como medio para transformarlo.

La defensa de una pedagogía popular, de raíces freinetistas, era intrínseca al proyecto. Se consideraba que la escuela no podía aislarse del entorno comarcal en el que se encontraba ubicada, y que se intentaba transformar en positivo, para lo que se formaban jóvenes agricultores comprometidos social y políticamente. Además, su influencia se extendía al entorno del alumnado, tanto a los padres, para hacerlos protagonistas del proceso educador de los hijos, como a todas las personas que quisieran participar en la transformación social.

Partiendo de esta premisa se entiende su proyección al exterior, en buena medida mediante los cursillos nocturnos de formación profesional para adultos, en donde, al mismo tiempo que se intentaban compensar las deficiencias de conocimientos básicos, se impartían nociones de cooperativismo, contabilidad, gestión y organización de las explotaciones agrícolas. En ellas así como en las reuniones de agricultores convocadas por los monitores de las escuelas, se encuentra el germen de la Unió de Llauradors i Ramaders del País Valencià, ${ }^{32}$ el sindicato más importante de

\footnotetext{
${ }^{31}$ Juan Vicente Blasco Canet, «Las cooperativas de enseñanza. Sociedad Cooperativa de enseñanza La Safor. Beniarjó» (Tesis de Licenciatura, Escuela Social de la Universitat de Valencia, 1987), 65.

32 Josep María Soriano Bessó, La Unió de llauradors (Alberic: J. Huguet Pascual, 1977).
} 
agricultores en tierras valencianas, que debe a las Escuelas agrícolas y a sus responsables buena parte de su existencia.

Rafael Gil resume los objetivos de la escuela en: «unir formación y asentamiento de población; compromiso comarcal; encontrar formas de vida y procesos productivos nuevos; estrechar lazos de unión del alumno con su entorno; raigambre del profesorado en la comarca y compromiso social». ${ }^{33}$

Si los desarrollamos podemos observar que en Chulilla se intentó:

- Unir formación y asentamiento de la población, posibilitando que el alumnado al formarse en el tema agrario, no tuviera que emigrar y pudiera continuar viviendo dignamente en sus pueblos de nacimiento o residencia.

- Un compromiso social y comarcal: que la escuela participara de manera activa y se implicara dando a conocer su opinión y haciéndose escuchar en temas sociopolíticos, económicos y culturales que afectaran a la comarca, incidiendo en ella pretendiendo impulsar una conciencia democrática.

- Encontrar formas de vida y procesos productivos nuevos: impulsar nuevos cultivos y fomentar la creación de empresas que permitieran un asentamiento en la comarca.

- Estrechar lazos de unión del alumnado con su entorno a través de la creación de cooperativas y asociaciones de carácter agrícola, cultural, medio ambiental..., así como favorecer la implicación en las instituciones como ayuntamientos, mancomunidad, etc.

- Arraigar el profesorado en la comarca, implicándolo en los problemas de la misma, llegando no solo al alumnado sino también a los padres.

\section{Presupuestos pedagógicos y su desarrollo en la práctica}

La escuela de la Serranía, mantenía para los temas organizativos y pedagógicos una estrecha coordinación con los centros de Catarroja y de Beniarjó, así como con la CFR, por lo que asistían a las reuniones de

\footnotetext{
${ }^{33}$ Entrevista de los autores al monitor de la escuela de Chulilla, Rafael Gil Cortés (27/02/2009).
} 
Tudela, en calidad de coordinadores, Rafael Gil y Benet Delcán, siendo Benet el coordinador de ambos proyectos.

Fruto de esta identificación con el modelo de las CFR, ponían en práctica, adaptándolos a su realidad, los principios que las caracterizaban.

Así, la alternancia, una de las aportaciones más originales de las Maisons, comporta coordinaba escuela y vida al alternar los períodos temporales de estancia en el centro escolar y en el propio domicilio, residiendo una semana en cada uno.

Con ello se permitía que el alumno no perdiera el contacto con el medio familiar y social, prolongándose mutuamente escuela y vida. La estancia en la escuela implicaba la existencia del régimen de internado, residiendo a tiempo completo durante la semana correspondiente, alumnado y educadores. Es decir, la convivencia durante las 24 horas del día, al pernoctar en ella, permitía establecer unas relaciones que rompían, en gran medida, las tradicionalmente jerarquizadas de profesor-alumno.

Albert Taberner resume así este proceso de aprendizaje:

en l'alternança, nosaltres creiem que aprendre d'una manera intensiva durant una setmana tenia els seus efectes, i que l'altra setmana els adolescents adoptarien compromisos socials, primer en la seua família ajudant a treballar, i aprenent del treball agrari que els pares podien ensenyar-li, podia donar un gran resultat, i de fet, creiem que era una mesura molt encertada. ${ }^{34}$

Esta concepción educativa favorecía la adopción de una metodología activa, que se concreta en el cuaderno de explotación familiar o cuaderno del medio, un instrumento de trabajo en el que se desarrollaban centros de interés, partiendo del medio natural y social, que abarcaba diferentes aspectos del entorno social, geográfico, económico e histórico, siempre considerando las necesidades de los adolescentes. Con él se facilita un estudio basado en la realidad cotidiana a través de la combinación entre teoría y práctica, que permite un aprendizaje significativo, potenciando el papel de monitores y padres.

\footnotetext{
${ }^{34}$ Entrevista de los autores al monitor de la escuela de Catarroja Albert Taberner (14-02-2008).
} 
Hay que tener presente que el currículum, con los contenidos a trabajar venían establecidos por ley, pero en los CFR se agrupaban en bloques de materias, siendo áreas de conocimiento globalizadas que se desarrollaban siguiendo la metodología de los centros de interés. Eran tres áreas: Ciencias Naturales (Biología, Física y Química), Ciencias Sociales (Historia, geografía, política y religión) y Lenguaje o materias instrumentales (Lengua y literatura y matemáticas). A ellas debe añadirse el área técnica. En el caso de la rama agraria, los centros de interés eran el hombre, la familia, la explotación, el trabajo, el pueblo, la comarca y la región.

Para el aprendizaje de contenidos de carácter teórico se utilizaban algunos libros de texto tradicionales — propiedad del centro docente-; pero, sobre todo, materiales elaborados por la CFR desde Valladolid, bien en forma de manuales o de sugerencias de trabajo que eran adaptadas por el profesorado a las características de la zona, lo que implicaba su confección artesanal mediante técnicas de multicopista o de coca de gelatina. Como recuerda Benet Delcán, el hecho de utilizar la multicopista, que era propiedad de una parroquia, o el método hectográfico, iba más allá de las dificultades económicas, porque varios monitores estaban vinculados al Movimiento cooperativo de escuela popular, que seguía las técnicas Freinet:

el tema de la impremta escolar... no era tant un problema econòmic sino un problema de una d'una manera d'entendre l'educació que, fins a cert punt, rebutjava tots els circuits comercials dels llibres..., pero sí que gastavem alguns, sobretot en materies més de tecnologia agraria agrària o de física. ${ }^{35}$

Por lo tanto, a los libros de texto más tradicionales, los proporcionados por la CFR, y los materiales realizados por los propios monitores, debía añadirse la utilización de los cuadernos del medio, técnica heredada de las Maisons que era la más utilizada, y en la que se trataba cada tema según la metodología de encuesta.

Este procedimiento de enseñanza-aprendizaje, combina la alternancia y el cuaderno configurando un proceso educativo que sigue una se-

\footnotetext{
${ }^{35}$ Entrevista de los autores a Benet Delcán Zamudio, monitor de la escuela de L'Horta y coordinador con la escuela de La Serrania (11/03/2008).
} 
cuencia general fija, que se inicia cuando el monitor introduce un tema y plantea cuestiones a resolver; que son completadas a continuación por las que propone el alumnado, estableciéndose un diálogo que cristaliza en un guión de trabajo o encuesta que se entrega a cada alumno.

Posteriormente, de manera individual o en grupo, el alumnado trata de resolverlo durante la estancia en casa, mediante la entrevista a personas y organismos que puedan darle respuestas. Con ello se amplia el diálogo a la familia y al vecindario, implicándolos en el proyecto, en una apuesta por el diálogo entre personas de diferentes edades, formaciones $\mathrm{y}$ experiencias vitales.

Cuando regresan a la escuela, monitor y alumnos se encuentran para poner en común el trabajo y elaborar las conclusiones; es decir, los resultados eran expuestos y debatidos de manera colectiva. Una vez establecidas las conclusiones, y tras corregir cada alumno sus fallos, pueden ser completadas con visitas relacionadas con el tema de estudio, quedando finalmente plasmadas en su propio e individualizado cuaderno del medio.

Una vez finalizado, el Cuaderno del medio constituía un útil resumen personalizado del trabajo desarrollado por cada alumno, lo que le permitía realizar el seguimiento y la evaluación continua de sus avances. Además, al reemplazar a los libros de texto, invitaba a la investigación y a la toma de conciencia, porque, como sugiere Paulo Freire, se trataba de sustituir la tradicional pedagogía bancaria por la liberadora, humanizando al alumno y haciéndolo consciente de la realidad que le rodea y de su situación en ella.

Así pues, en la semana que residía en su domicilio, el alumno compaginaba el trabajo en el cuaderno con las prácticas reales en la explotación agrícola familiar, en donde aplicaba la tecnología aprendida en la Escuela, y era visitado por su monitor-tutor, quien observaba el ambiente en que vivía y podía intercambiar opiniones con la familia, completando un proceso de aprendizaje no sólo de carácter intelectual, sino, fundamentalmente, de formación humana.

El tercer pilar de los presupuestos pedagógicos y metodológicos de la escuela agraria de Chulilla es el de la cogestión y el trabajo en equipo, en el sentido de participación de la comunidad educativa en el proyecto. Por una parte, al ser la entidad promotora y propietaria jurídicamente 
de cada escuela la Asociación de Padres, implicaba a estos no sólo en la gestión y administración, sino también pedagógicamente, creando unos organismos en los que los educadores, que pasaban a denominarse monitores, gozaban de gran protagonismo, guiando y orientando en lugar de imponer contenidos; por su parte, los alumnos colaboraban en la elaboración de los programas.

Cabe citar, entre las prácticas democráticas, que las tareas de mantenimiento de la escuela eran asumidas por monitores y alumnos, configurando equipos mixtos en los que trabajaban conjuntamente con igual nivel de exigencia, lo que fomentaba la cooperación y unas buenas prácticas de convivencia que eran potenciadas al vivir los monitores con los alumnos en régimen de internado, favoreciendo la formación personalizada.

El principio de cogestión se convierte en práctica de democracia, haciendo que participe y se implique la comunidad educativa desde la doble perspectiva de gestión y de toma de decisiones pedagógicas.

Las decisiones de carácter económico, organizativo y pedagógico eran tomadas por la Asamblea general, formada por todos los socios y padres de alumnos, que eran los propietarios. Para una mayor eficacia, delegaba sus funciones en la Junta Rectora, en la que también participaban representantes del profesorado y a la que podían asistir alumnos para informar, y si bien sólo se realizaba una asamblea general a principio y otra a final de curso, la Junta Rectora se reunía cada uno o dos meses, lo que permitía un seguimiento más cercano e ir encontrando soluciones según surgían los problemas.

Desde una perspectiva pedagógica, el Equipo pedagógico confeccionaba un plan anual que se iba concretando con la colaboración del alumnado. Por su parte, a los padres se les implicaba a través de reuniones donde se les informaba de la marcha de la escuela y sus actividades, y, según las posibilidades de los centros docentes, se organizaban encuentros para discutir sobre aspectos educativos, mediante la lectura de artículos o la exposición, por parte de alguna persona externa al centro, de temas de interés como las drogas, la sexualidad, la relación padres-hijos, el alcoholismo, etc. 
Democracia significaba, así mismo, que la autoridad se basaba en las premisas de igualdad y confianza, a base de diálogo y la convocatoria de asambleas para la toma de decisiones en las que cada miembro tenía un voto, siendo indiferente su condición de alumno o monitor.

También democráticamente los monitores se encargaban de la intendencia y la cocina preparando siempre los desayunos; se compartían las tareas de limpieza del comedor y de las habitaciones, compra de suministros, pequeñas reparaciones..., que eran asumidas por equipos de trabajo formados por monitores y alumnos.

Debe remarcarse el valor educativo de estas tareas, tanto por fomentar la cooperación, en la línea que planteaba Makarenko, como por contribuir a romper los esquemas de género, al ser ejecutados por mujeres y hombres indistintamente. Además, se acostumbraban a hábitos de orden y limpieza, se hacían responsables de su tarea y se creaba la sensación de que la escuela era algo suyo.

Finalmente, otra influencia pedagógica de esta experiencia de educación agraria de Chulilla, especialmente en su última etapa, fueron los postulados de Alexander Sutherland Neill y su experiencia de Summerhill. La escuela en libertad responde con precisión a los rasgos definitorios de esta cooperativa de enseñanza: antiautoritaria, asamblearia, fomentadora de una toma de conciencia crítica, donde se practicaba una pedagogía activa, en contacto con la naturaleza, que respetaba y educaba los sentimientos, y que potenciaba la autonomia del alumnado. Una escuela abierta y participativa donde los debates y las contradicciones se intentaban superar democráticamente. Vicent Borrás reconoce que la influencia de Freire y Freinet era importante, pero fundamentalmente, la ascendencia de Neill impuso su sello distintivo:

[...] recorde a Neill. Allò era casi l'escola de Summerhill, era semblant a Summerhill. Els alumnes arribaven a tindre els mateixos problemes que tenien els alumnes de Summerhill, perquè al final eixe poder, eixa llibertat de fer el que vullgueren, en el moment que vullgueren ... mentre tu tenies que anar a convencer-los, de que tenien que estudiar, que esta setmana no has estu- 
diat i tal i qual, no, és que no m'apeteix... Unes discussions..., ens passaven la vida discutint, i convencent, i argumentant. ${ }^{36}$

\section{El día a día de la escuela}

En la cooperativa de enseñanza de Chulilla, como hemos indicado, se llevó a la práctica una metodología integral y global, que, partiendo de los intereses del alumnado y de la realidad del medio, intentaba conseguir una formación integral, para lo que se utilizaba la alternancia y el cuaderno del medio para poder adquirir los contenidos decretados por el Ministerio de Educación, pero en un clima lúdico y de libertad que los hará especialmente atractivos.

El curso comenzaba con la elaboració de un plan anual de contenidos. Antes de su comienzo, el Equipo pedagógico, confeccionaba una planificación que seguía las líneas generales dadas por el Ministerio, ya adaptadas por el equipo de Valladolid. Se iba concretando mensualmente, con la colaboración del alumnado, y cada mes, semana por semana, se distribuían las tareas a realizar entre los días que acudían a su domicilio y los que permanecían en la escuela. Al finalizar la semana, el profesorado revisaba su trabajo, planificaba actividades y elaboraba los materiales necesarios.

En la semana que estaban en su casa, el alumnado trabajaba el cuaderno del medio y llevaba a cabo prácticas de técnicas agrícolas, siendo visitados por los monitores en una o dos ocasiones. Cuando permanecían en la escuela, en régimen de internado, seguían unas pautas regladas, de manera que el día a día de la escuela podría ser el siguiente:

- Por la mañana, la jornada empezaba a las siete, cuando se levantaban y desayunaban tanto alumnado como educadores. Después realizaban tareas de limpieza y empezaban las clases en las que se impartían las materias preceptivas del grado, utilizando las metodologías activas ya citadas.

- A mediodía se realizaba una pausa para comer. Tras ella, monitores y alumnado distribuidos en equipos rotativos y mixtos com-

\footnotetext{
${ }^{36}$ Entrevista de los autores al monitor de la escuela de Chulilla, Vicent Borrás Sena (10/06/2008).
} 
partían las tareas de mantenimiento aprobadas semanalmente en la asamblea.

- Las siete de la tarde era la hora fijada para acabar las clases, tras las cuales, en ocasiones paseaban. Al volver cenaban y se acababa la jornada, excepto los viernes que era el día destinado a la celebración de la asamblea, realizando posteriormente actividades de carácter lúdico y tiempo libre. En la asamblea se analizaba la semana y se planificaba la siguiente con la participación de profesorado y alumnado. Se distribuían las tareas entre los grupos y se decidían las posibles sanciones para aquellos que habían cometido alguna falta, posibilitando una enseñanza y convivencia participativa y asamblearia. Vicent Borrás recuerda que cada cual era responsable del trabajo que tenía asignado y su cumplimiento era exigido con mucha firmeza por la asamblea:

en quan participen els alumnes no te'n deixaven pasar ni una, ells eren molt durs i al mateix temps que s'exigien a ells mateixa, t'exigien a tu (els monitors). I eren nanos de 14 anys o siga que hi havia totes les setmanes una assemblea de alumnes i de professors, en la qual s'establien pues un poc el funcionament de la setmana següent, s'analitzava lo que haviem fet durant eixa setmana i possavem una serie de tasques a fer i una serie de càstics a qui no cumplia. Que jo recorde que per la meua dedicació una vegada tenia assignat netejar els cristals i les persianes de l'escola i no ho vaig fer i els mateixos alumnes em castigaren a fer-ho 15 o 20 dies seguits. ${ }^{37}$

El tercer año alumnos y monitores cocinaban al no disponer de ayuda externa. Muchas veces se llevaba la comida a cocinar al horno público. Siempre se compraba en el pequeño comercio, o bien se compraban productos de proximidad a los cosecheros.

El antiautoritarismo era una de las características del centro, acentuándose en el tercer curso al trasladarse a Villar del Arzobispo. Allí Ximo Sánchez, valorando la experiencia como muy positiva, declara que se llegó a conseguir un asambleísmo puro, pero aparecieron conflictos entre todos los sectores, al existir debates continuos para superar las di-

\footnotetext{
${ }^{37}$ Entrevista de los autores al monitor de la escuela de Chulilla, Vicent Borrás Sena (10/06/2008).
} 
vergencias. Y es que la escuela estaba llena de contradicciones por el hecho de tener una escala de valores diferente al resto de la sociedad. Al fin y al cabo sería esta una de las razones que dificultaría la continuidad del proyecto. ${ }^{38}$

En lo relativo al carácter confesional o no de la escuela, cabe diferenciar entre cursar la asignatura de religión y las prácticas religiosas. Al estar todavía incluida la religión católica en el currículum oficial de manera obligatoria, fue el sacerdote de Chulilla quien la impartió en el primer año. Sin embargo, ni alumnado ni profesorado asistían a la celebración de la misa pese a la buena relación y el contacto continuo con los sacerdotes, los cuales eran, por otra parte, quienes en buena medida los apoyaban. Esta relación no significó nunca imposición, ni los llevó a inmiscuirse en la realización o no de prácticas religiosas por parte de la comunidad educativa.

Otro rasgo distintivo de la escuela es que desde el primer momento fue coeducativa. La cantidad de mujeres que asistían era importante porque en el tiempo que residían en la escuela estaban en régimen de internado y dormían allí, un hecho que demuestra la confianza de los padres en las hijas y los monitores, al ser un internado mixto, si bien con habitaciones de chicas y chicos diferenciadas.

Coeducar significó también otorgarle gran importancia a la educación sexual. Chicos, chicas y monitores, algunos días tras la comida, leían y debatían libros de sexualidad de Wilhem Reich, reflexionando sobre la vida y el sexo.

A las alumnas se las hacía tomar conciencia de su igualdad de capacidades con los alumnos, así como de la necesidad de luchar contra la discriminación por el hecho de ser mujeres.

La liberación de las mujeres, la necesidad de educarse, el derecho a ejercer cualquier profesión y las desigualdades laborales eran temas que se debatieron y trataron en la escuela, y que se vieron reflejados en sus escritos, publicados en el boletín informativo de las cooperativas de enseñanza agrícola Agricultura Jove.

\footnotetext{
${ }^{38}$ Entrevista de los autores al monitor de la escuela de Chulilla, Ximo Sánchez (7/06/2008).
} 
La alumna Mercedes García, centraba sus críticas en la división de trabajo por razón de género transmitida y perpetuada por el sistema escolar: "la escuela ha educado siempre de forma distinta a los chicos y a las chicas. A nosotras nos ha tocado siempre fregar las clases o hacer costura; los chicos sólo hacían trabajos que necesitaban fuerza».

Otra alumna, Mari Carmen García, reivindicaba la posibilidad de ejercer las mujeres un trabajo remunerado que les permitiera una suficiencia económica, incluso después de haber contraído matrimonio, porque la independencia económica era un paso hacia la liberación personal: «La mujer debe trabajar incluso después de casada, no debe esperar que la mantenga el marido. La mujer empieza a liberarse cuando comienza a trabajar fuera de casa. El trabajo le da seguridad, le hace sentirse útil a la sociedad».

Ahora bien, como apunta Rosa María Alcaide, este trabajo no puede hacerse a cualquier precio, por lo que debe denunciarse la explotación laboral de las mujeres y exigir que se termine con el trabajo a domicilio, injustamente pagado y que excluye a las trabajadoras de la Seguridad Social:

Cuando la mujer hace trabajos en casa para la industria, como coser, tricotar, etc... se le paga muy poco por las piezas que hace y además no se le paga la seguridad Social, con lo cual el comerciante o "empresario» obtiene muy buenos beneficios sin exponer apenas capital.

Como resumen de la formación en clave feminista que la escuela realizaba, reproducimos el texto de M. ${ }^{a}$ Joaquina Muñoz, en el que, bajo el epígrafe «La mujer en el medio rural», denuncia la falta de trabajos para las mujeres, incluso las capacitadas profesionalmente y la discriminación salarial por razón de género, reivindicando la igualdad de capacidades y la formación y cualificación profesional de ellas:

En nuestra comarca no hay puestos de trabajo para las mujeres, y tampoco para las chicas que salimos de la escuela. Por otra parte, cuando lo encontramos ocasionalmente estamos discriminadas con el hombre, cobrando mucho menos. Yo creo que a igual trabajo debe darse igual salario. 
Creo que la mujer tiene igual capacidad mental que el hombre, pero la sociedad no acepta su igualdad. Son pocas las mujeres que alcanzan una cualificación profesional, y esto no será posible mientras no hayan escuelas profesionales en los pueblos. ${ }^{39}$

Otra característica de la escuela de Chulilla, en la que se asemeja a la de Lorenzo Milani en Barbiana, es que estaba abierta a visitantes que podían aportar diferentes experiencias. La mayoría eran amigos de los monitores. Podemos recordar al sociólogo Josép Vicent Marqués que residió allí una semana, al cantante Luis Pastor u otras personas que acudían y les enseñaban, por ejemplo, a tejer y tintar el tejido.

También se permitía hacer oír su propia voz al alumnado cuando, de manera periódica, se participaba en la elaboración de una publicación ciclostilada, Agricultura Jove en la que podían escribir todos los miembros de la comunidad educativa.

Finalmente cabe apuntar que el arraigo a la tierra comportaba un compromiso social, evidente en la implicación de los monitores en la tarea de impulsar la creación del sindicato la Unió de Llauradors, y en la de dinamizar listas municipales para las elecciones a los primeros ayuntamientos democráticos en 1979.

La apertura de la escuela coincidió con la necesidad de montar, difundir y consolidar la Unió de Llauradors, organizando reuniones en los pueblos con los labradores para intentar concienciarlos y que se organizaran en un sindicato propio. Vicent Borrás recuerda organizar a los labradores e incluso, cuando se redactaron los diez puntos fundacionales de la Unió, animarles a que no se redujeran a reivindicaciones estrictamente de carácter económico, sino que incluyesen también otras de carácter político y social como, por ejemplo, la reivindicación del estatuto de autonomía valenciano. ${ }^{40}$

La práctica de la alternancia facilitó esta tarea, pues a la hora de las tutorías los monitores podían hablar con los padres, planteándoles temas

\footnotetext{
39 «Parlen els alumnes. Xulilla», Agricultura Jove. Boletín informativo de las cooperativas de enseñanza Escuela de Formación Agrícola Comarcal L'Horta-Catarroja; La Serrania-Chulilla; La Safor-Beniarjó, 12 (diciembre 1977, enero 1978): 6.

${ }^{40}$ Entrevista de los autores al monitor de la escuela de Chulilla, Vicent Borrás Sena (10/06/2008).
} 
relacionados no solamente ni de manera estricta con la formación de sus hijos.

El nivel de confianza entre padres y monitores facilitaría su organización sindical y, al mismo tiempo, una toma de conciencia política que se vería reflejada en las primeras elecciones municipales, a las cuales se presentaron listas promovidas por los monitores ante la necesidad de acabar con el caciquismo existente en algunas poblaciones.

\section{EL FINAL DE UNA EXPERIENCIA PEDAGÓGICA DE FORMACIÓN PROFESIONAL AGRÍCOLA Y BALANCE DE LA MISMA}

La experiencia de Chulilla tuvo un final repentino e inesperado en 1979 siendo tres las causas principales del cierre:

- La inauguración en Villar del Arzobispo, en 1977, de un centro de Formación profesional, que supuso una fuerte competencia a la hora de captar el alumnado.

- La no concesión, por parte del Ministerio de las becas que permitían sufragar los gastos de funcionamiento, lo que provocó el no poder pagar el alquiler del albergue.

- La negativa, por parte de la inspección educativa y de las autoridades municipales de Villar, a aceptar la propuesta de crear una residencia «Familiar» en Villar para los alumnos de los pueblos del resto de la comarca con el fin de no desligarlos de esta, de no des-localizarlos. ${ }^{41}$

Como consecuencia, en el curso 1978-1979 ya no se matricularon nuevos alumnos y los que componían la segunda promoción tuvieron que trasladarse a Villar del Arzobispo, en donde se alquilaron dos casas adosadas, instalándose en ellas el internado y las aulas. La práctica de medidas originales (cría de gallinas, venta de los productos agrícolas por ellos cultivados) y el fortalecimiento de la solidaridad entre el alumnado, los monitores y la población, permitieron que los alumnos obtuvieran el título de formación profesional.

En estas circunstancias adversas, además de asistir a clase y desarrollar la programación académica, alumnado y profesorado debían realizar

\footnotetext{
${ }^{41}$ E-mail del monitor de la escuela de Chulilla, Rafael Gil Cortés (29/12/2012).
} 
todas las tareas domésticas, agrícolas y avícolas organizándose en turnos rotativos. La implicación del pueblo permitió que la escuela hiciera tareas de dinamización con los vecinos, extendiendo las actividades culturales del viernes por la noche a todo el vecindario, con el que se compartían momentos de ocio. La escuela se abrió y extendió su labor cultural al pueblo de forma que educaba a todo el mundo, era «una escuela abierta al mundo». ${ }^{42}$

Una vez acabado el curso 1978-1979, la escuela cerró sus puertas, con un balance agridulce por parte de los monitores entrevistados. Rafael Gil comenta que desde primera hora existían problemas que fueron agravándose con el paso del tiempo. ${ }^{43}$ Algunos han sido apuntados como la ubicación de la escuela en Chulilla, que dificultaba los desplazamientos, los de carácter económico, agravados por la no concesión de becas, y, los recelos por parte de las autoridades municipales, identificadas con el franquismo, provocados por las actividades y el compromiso social que los educadores desarrollaban.

Este recelo condujo a la creación de un ambiente negativo que dificultó e incluso impidió en algunos casos el apoyo económico de asociaciones y entidades de la zona, dando como fruto el boicot a una experiencia considerada subversiva y peligrosa.

Otras dificultades tenían una base más pedagógica: no existían talleres, hubo una carencia de visión profesional y no se tuvo en cuenta el descenso de la población, lo que dificultó la matrícula mínima necesaria, así como la falta de experiencia previa de los monitores que se fueron incorporando con posterioridad.

Sin embargo, hubo muchos aspectos positivos. Rafa Gil destaca la socialización de las becas, la práctica de la coeducación, el hecho de encontrarse alumnos de diferentes pueblos alejados, la buena relación con los agentes sociales, en especial entre monitores y sacerdotes, el hecho de que el alumnado consiguiera al finalizar los estudios un puesto de trabajo, así como un compromiso social y medioambiental, etc. Además, la escuela participó y colaboró en la conformación de los primeros ayunta-

\footnotetext{
${ }^{42}$ Entrevista de los autores al monitor de la escuela de Chulilla, Ximo Sánchez (7/06/2008).

${ }^{43}$ Entrevista de los autores al monitor de la escuela de Chulilla, Rafael Gil Cortés (27/02/ 2009).
} 
mientos democráticos, en la creación y difusión de la Unió de Llauradors y en la extensión cultural.

Vicent Borrás apunta la participación y la creación de un pensamiento crítico como las aportaciones que más agradecieron los alumnos:

van poder decidir en cada moment el que es feia, perquè se feia, el realitzar una análisi continua del feiem allí, el fet d'haver-les ajudat a crear una consciencia crítica, el ser homes crítics en la vida, davant les coses pensant perquè ho fan, on van, perquè allò se va inculcar molt bé i clar. ${ }^{44}$

Ximo Sánchez comparte el sentimiento de que la escuela cambió su vida, fue una vivencia muy intensa desde todos los ámbitos al estar las veinticuatro horas del día trabajando y aprendiendo junto al alumnado y la comunidad.

La creación de las escuelas no puede desvincularse del tiempo y las circunstancias políticas en que se produjeron, y que tuvieron gran incidencia en su desarrollo, pues hubieron de superar graves dificultadas para su supervivencia. La práctica de una educación que no se limitaba a la mera transmisión de conocimientos, sino que era liberadora, crítica e intentaba transformar el medio natural y social, así como sus indudables vínculos con los movimientos socio-políticos de izquierdas, provocaron una disminución de la matrícula y la falta de colaboración de las instituciones franquistas en una experiencia docente que consideraban transgresora.

Así pues, tras el estudio de esta iniciativa pedagógica valenciana de formación profesional agrícola en el período político de la transición, podemos concluir que se trató de una experiencia de gran impacto tanto pedagógico como social para todos sus protagonistas. El desarrollo de una escuela democrática, en la que se ejercía la libertad, la participación política, el arraigo al medio, el contacto directo con la comunidad y la educación integral, es una muestra que nos ofrece la historia de la educación de cómo llevar a la práctica e implementar principios pedagógicos y democráticos por un grupo ilusionado y con ganas de trabajar por la dinamización y mejora de su entorno rural más cercano.

\footnotetext{
${ }^{44}$ Entrevista de los autores al monitor de la escuela de Chulilla, Vicent Borrás Sena (10/06/2008).
} 


\section{Nota sobre los autores}

M. ${ }^{a}$ Del Carmen Agulló Díaz es Doctora en Filosofía y Ciencias de la Educación. Profesora Titular del Departamento de Educación Comparada e Historia de la Educación de la Universitat de València. Sus ámbitos de investigación son la historia de la educación de las mujeres, la historia de la educación valenciana durante la Segunda República y el franquismo y la recuperación del patrimonio histórico-educativo. Es vicepresidenta de la Societat d'Història de l'Educació dels Països de Llengua Catalana.

ANDRÉs PAyÀ Rico es Profesor Contratado Doctor (acreditado a Titular de Universidad) y Director del Departamento de Educación Comparada e Historia de la Educación de la Universitat de València. Profesor consultor de Historia de la Educación social en la Universitat Oberta de Catalunya. Sus ámbitos de investigación son la historia de la educación española y valenciana contemporánea, el juego y el juguete en la educación, así como la innovación docente y la didáctica de la historia de la educación.

\section{Referencias}

Agulló DíAZ, M. a del Carmen. «De ignorada a necesaria: la formación profesional de las mujeres en el franquismo (1936-1975)». In Entre lo doméstico y lo público. Capacitación profesional de las mujeres rurales en España (1940-1977), edited by Sara Ramos Zamora. Madrid: Biblioteca Nueva, 2016.

Agulló DíAz, M. ${ }^{a}$ del Carmen y Andrés Payà Rico. "La influencia de las Maisons familiales d'apprentissage rural en las escuelas comarcales de formación agrícola valencianas (1973-2008)». In Influencias francesas en la educación iberoamericana (1808-2008), edited by José María Hernández Díaz, 275-288. Salamanca: Globalia Ediciones Anthema, 2008.

- Les cooperatives d'ensenyament al País Valencià i la renovació pedagògica $i$ social (1968-1976). Valencia: Universitat de València, 2012.

- «La Nostra Escola Comarcal: An Educational Cooperative in Defense of Democratic, Active and Valencian Pedagogy (Spain: 1973)». In Pedagogies and Curriculums to (Re) imagine Public Education, edited by Encarna Rodriguez, 187-202. New York: Springer, 2015.

- Les cooperatives d'ensenyament al País Valencià $i$ la renovació pedagògica $i$ social (1968-1976). Valencia: Universitat de València, 2012.

Almendros, Herminio. «La escuela rural». Revista de Pedagogía 145 (1934): 6-14. 
Blasco CANet, Juan Vicente. «Las cooperativas de enseñanza. Sociedad Cooperativa de enseñanza La Safor. Beniarjó». PhD diss., Escuela Social de la Universitat de Valencia, 1987.

Fernández Soria, Juan Manuel y M. ${ }^{a}$ del Carmen Agulló DíAz. «El Problema de l'escola rural durant la Segona República». Educació i història: Revista d'història de l'educació 8 (2005): 29-62.

GonzÁlez-AgÀPito, Josep, Salomó Marqués, Alejandro Mayordomo y Bernat SuREDA. Tradició i renovació pedagògica. 1898-1939. Barcelona: Institut d'Estudis Catalans. Publicacions de l'Abadia de Montserrat, 2002.

La Escuela Nueva Unificada. Recopilación de antecedentes, comentarios y juicios críticos, junto con la obra desarrollada bajo los auspicios del CENU desde el 19 de julio de 1936. Barcelona: Ediciones Españolas de la Revolución, 1938.

MuÑoz PEINADO, Jesús. «Los colegios familiares rurales». Revista Interuniversitaria de Formación del profesorado 17 (3), (2003): 75-89.

PAYÀ Rico, Andrés. «Formació professional, instrucció i adoctrinament a l'empresa Segarra (la Vall d'Uixò, Castelló) durant el franquisme». Educació $i$ Història. Revista d'història de l'educació 15 (2010): 229-252.

Soriano Bessó, Josep María. La Unió de llauradors. Alberic: J. Huguet Pascual, 1977. 